\title{
TRIBUTE TO PROF. CARLOS DA SILVA LACAZ
}

\author{
Thelma Suely OKAY(1)
}

The Revista do Instituto de Medicina Tropical de São Paulo has the honor to present this special issue of the year 2015 that is entirely dedicated to celebrate the centennial anniversary of Prof. Carlos da Silva Lacaz, founder of the Instituto de Medicina Tropical. Simultaneously to the creation of the Institute, the Revista do Instituto de Medicina Tropical de São Paulo also began to operate in 1959, initially led by Prof. Luiz Rey, succeeded by Prof. Lacaz himself until 1985, and afterwards by Prof. Thales de Brito for 30 years, until May, 2015. Therefore, it was just recently that I am leading the Revista do Instituto de Medicina Tropical de São Paulo. Nonetheless, I would like to give my testimony on the short, but fruitful interaction I had with Prof. Lacaz.

Despite being a former student of the Faculdade de Medicina da Universidade de São Paulo, I did not have the good fortune to be his undergraduate student. I met him many years later, after returning from abroad (France) where I did my PhD thesis on cellular and molecular biology. I worked for some time in the Immunology Laboratory which is located on the same floor of the Mycology Laboratory that was, at that time, headed by Prof. Lacaz. With him I learned much medicine, history of medicine, the correct use of the Portuguese language, among other things. Prof. Lacaz availability caught my attention and as he requested private tutoring in molecular biology, I must say that he was, as always, a brilliant student. Another of Prof. Lacaz features was his willingness to teach and help people. Prof. Lacaz has always taken the Hippocratic Oath very seriously, and was deeply sorry that medical students and their teachers were moving away from humanistic values that he believed, were essential to all medical doctors. He was a tireless defensor of the Faculdade de Medicina and the Instituto de Medicina Tropical in all important issues for the two institutions.

Working in the laboratory next door gave me the opportunity to change ideas with Prof. Lacaz, and these experiences have always been very enriching because he owned a remarkable good humor, wit, creativity, critical thinking, leadership, and an ability to analyze and solve problems revealing an intelligence and dynamism that unfortunately we do not see nowadays. This coexistence left me a legacy represented by several autographed books with formidable dedications, many hand notes with tips of all kinds, on matters of day-to-day and life, or on scientific research. Whenever I feel discouraged, I read these notes and Prof. Lacaz dedications and realize how, even without having had the intention, Prof. Lacaz made me a better person. I thank him for all the nice moments of coexistence, for all the encouragement I received and I hope he enjoys this tribute of the Revista do Instituto de Medicina Tropical de São Paulo that he has helped to create and develop.

In the following pages our readers will find, initially, a moving testimony on the professional career and achievements of Prof. Lacaz. Next, several review articles on the most stimulating topics of current Medical Mycology, written by highly qualified professionals who work in various countries, many of them former students and friends of Prof. Lacaz. The Revista do Instituto de Medicina Tropical de São Paulo thanks all these valuable colleagues and also the researchers who are currently leading the Mycology Laboratory of the Instituto de Medicina Tropical and have selected the topics to be addressed in this special issue, Prof. Gil Benard, Prof. Carlos Pelleschi Taborda and Dra. Gilda M.B. Del Negro.

I conclude reproducing one of the famous Professor Lacaz phrases that he has left as a legacy to all those who admire his life and work: it is always necessary to have "joie de vivre". And it is with "joie de vivre" that I will let you read the review articles that follow with the certainty that the privileged people that managed to capture Prof. Lacaz spirit will know how to enjoy them. 
THIS SUPPLEMENT OF THE

REVISTA DO INSTITUTO DE MEDICINA TROPICAL DE SÃO PAULO

DEDICATED TO THE

CENTENNIAL ANNIVERSARY OF

PROF. CARLOS DA SILVA LACAZ

(1915-2015)

WAS SUPPORTED BY

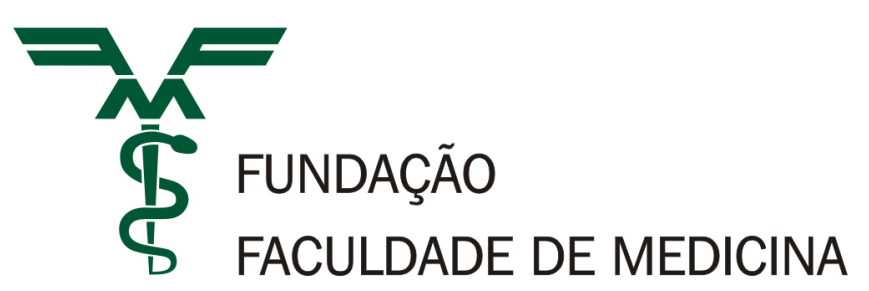

